\title{
A CRIANÇA, O JOGO E O LÚDICO NO PROCESSO DE ENSINO E APRENDIZAGEM
}

\section{THE CHILD, THE GAME AND THE LUDIC IN THE TEACHING AND LEARNING PROCESS}

\author{
Danilo Augusto Reinol ${ }^{1}$, Mario Marcos Lopes ${ }^{2}$, Emerson Benedito Ferreira ${ }^{3}$
}

Submetido em: $28 / 03 / 2020$

Avaliado em: $30 / 04 / 2020$

Aprovado em: 23/02/2021

\section{RESUMO}

O presente trabalho aborda a importância do lúdico no ambiente escolar, com o objetivo de evidenciar o papel do jogo como um recurso facilitador no processo de ensino e aprendizagem, reconhecendo-o como um importante instrumento pedagógico para o desenvolvimento cognitivo, físico, emocional e social. As atividades lúdicas são ferramentas valorosas na rotina do educador, pois auxiliam na elaboração de conceitos, na tomada de decisões, reforçam conteúdos, promovem a sociabilidade entre os alunos, desperta a criatividade, a imaginação, o raciocínio lógico, a fantasia, a cooperação, a oralidade, a autoestima, a autonomia e o respeito de maneira aprazível e atraente aos educandos, estabelecendo entre elas uma relação de aprendizagem mútua.

PALAVRAS-CHAVE: Desenvolvimento Infantil. Brincadeiras. Interação Social.

1 Pedagogo, professor da educação infantil na cidade de Taquaritinga-SP. Mestrando pelo PPGE-UFScar na linha Educação cultura e subjetividade. Atualmente pesquisa infância negra no pós-abolição.

${ }^{2}$ Mestre em Desenvolvimento Regional e Meio Ambiente pela Universidade de Araraquara (2011). Especialista em: Tecnologias e Educação a Distância (2016) pelo Centro Universitário Barão de Mauá, Educação Ambiental e Desenvolvimento Sustentável (2016), Gestão Estratégica de Pessoas (2015), Gestão Escolar (2013) e Didática e Tendências Pedagógicas (2011) pela Faculdade de Educação São Luís e Aperfeiçoamento em Educação Ambiental pela Universidade Federal de São João Del Rei - MG (2010). Graduação em Ciências Biológicas pelo Centro Universitário Barão de Mauá (2008) e Pedagogia (2016) pela Fatece. Atuou como Tutor e Orientador no Curso de Especialização em Educação Ambiental com Ênfase em espaços educadores sustentáveis oferecido pela Universidade Federal de São Paulo (UNIFESP). É professor-tutor e orientador de TCC dos Cursos de Especialização da Faculdade de Educação São Luís, além de ministrar aulas nas disciplinas de Gestão Ambiental e Metodologia do Ensino de Ciências. É docente nas disciplinas de: Tecnologia Educacional na Gestão do Conhecimento: Educação Continuada e Evolução Profissional; Metodologia da Pesquisa Científica; Planejamento, avaliação e metodologias em educação ambiental e orienta trabalhos de conclusão de curso de Especialização na área da Educação pelo Centro Universitário Barão de Mauá. Atua como Professor Coordenador (Secretaria de Estado da Educação. Correio eletrônico: lopesmmarcos@gmail.com

${ }^{3}$ Graduado em Ciências Jurídicas e Sociais (Direito) pela Universidade de Ribeirão Preto - (UNAERP - 1999). Licenciado em História pelo Centro Universitário Claretiano (2017). Licenciado em Pedagogia pela Unifacvest (2020). Especialista em Direito Educacional (2009), Filosofia da Educação (2011) e MBA em Gestão Estratégica de Pessoas pela Faculdade de Educação São Luis de Jaboticabal (FESL); Mestre e Doutor em Educação pela Universidade Federal de São Carlos - UFSCar na linha de pesquisa 'Educação, Cultura e Subjetividade’;

Desenvolve investigações vinculadas à linha de pesquisa 'Diferenças: relações étnico-raciais, de gênero e etária' e participa do grupo de estudos sobre 'a criança, a infância e a educação infantil: políticas e práticas da diferença' vinculado à UFSCar. Atua principalmente nas seguintes áreas: Estudos sobre a Infância e a criança, Sociologia da Infância, do Desastre e da Diferença. Tem interesse nos estudos sobre a história da infância e da criança, da família, da criança negra (escravizada e tutelada), criminalidade infantil, relações étnico-raciais, abolicionismo penal (tendência estrutural historicista de Michel Foucault), História da Educação no Brasil, História da Criminologia Infantil. correio eletrônico: emerson_ufscar@hotmail.com 


\section{ABSTRACT}

The present work addresses the importance of playfulness in the school environment, with the aim of highlighting the role of the game as a facilitating resource in the teaching and learning process, recognizing it as an important pedagogical tool for cognitive, physical, emotional development and social. Playful activities are valuable tools in the educator's routine, as they help in the elaboration of concepts, in decision making, reinforce content, promote sociability among students, awaken creativity, imagination, logical reasoning, fantasy, cooperation, orality, self-esteem, autonomy and respect in a pleasant and attractive way to students, establishing a mutual learning relationship between them.

KEYWORDS: Child Development. Play. Social Interaction. 


\section{INTRODUÇÃO}

Vivemos num momento em que muito se tem discutido e investigado a respeito de se refletir e de se analisar as práticas pedagógicas de ensino e aprendizagem, que proporcionem e resgatem nos educandos o prazer de se aprender de forma significativa e enriquecedora.

Usando dos ensinamentos de Maluf (2008), pode-se dizer que proporcionar atividades lúdicas no ambiente escolar é tarefa importante para o desenvolvimento das habilidades motoras, cognitivas, sociais, físicas, psicológicas e afetivas . Em termos similares, Macedo (2007, p. 07) entoa que "ao jogar, uma criança dá muitas informações e comunica, através da ação, sua forma de pensar, desde que o observador reconheça nas ações ou nos procedimentos os indícios que está buscando para realizar sua avaliação".

Nesta perspectiva, este trabalho pretende analisar as possíveis contribuições que as atividades com jogos e brincadeiras promovem no desenvolvimento dos educandos. Também pretende investigar se tais recursos, quando bem planejados no ambiente escolar, realmente proporcionam diagnósticos fundamentais sobre o comportamento geral de um determinado grupo ou indivíduo, e se apontam em que estágio de desenvolvimento se encontra a criança, se conhecem os seus valores, as suas ideias, os seus interesses, os seus pensamentos, as suas dificuldades e as suas necessidades, bem como, seus conflitos, problemas e potencialidades (FRIEDMANN, 2012).

À vista disso, quando se pensa atividades significativas e que causam desafios, deve-se levar em consideração a realidade sociocultural dos educandos, seus estágios de desenvolvimento e os processos de construção cognitiva, valorizando o acesso aos conhecimentos do mundo físico, social e afetivo (FRIEDMANN, 2012).

Nesse contexto, os jogos ganham um espaço como instrumento ideal na aprendizagem na medida em que estimulam nos alunos suas capacidades de raciocínio lógico, seu pensamento, enriquecem sua personalidade, constroem novas descobertas, proporcionam a comunicação e o respeito ás regras e aos seus próprios limites, despertam a criatividade e imaginação, ampliam o seu repertório linguístico, estimulam sua autonomia, independência, autoconfiança, motricidade, equilíbrio, coordenação, lateralidade, etc., possibilitando às crianças de descobrirem novos desafios que promovam uma educação de qualidade, que favoreça o desenvolvimento pleno e integral das crianças (BRASIL, 1998).

Para tanto, as brincadeiras e jogos são elementos indispensáveis para a formação plena e integral dos indivíduos, pois estas atividades proporcionam aos alunos que aprendem diversas temáticas e estudos de forma prazerosa, harmoniosa, dinâmica, segura e significativa, despertando nos mesmos a busca pelo conhecimento e aperfeiçoamento de suas relações interpessoais, sociais, afetivas e culturais (BRASIL, 1998).

Macedo (2007, p. 13-14) aponta que:

O brincar é fundamental para o nosso desenvolvimento. É a principal atividade das crianças quando não estão dedicadas às suas necessidades de sobrevivência (repouso, alimentação, etc.). Todas as crianças brincam se não estão cansadas, doentes ou impedidas. Brincar é envolvente, interessante e informativo. Envolvente porque coloca a criança em um contexto de interação em que suas atividades físicas e fantasiosas, bem como os objetos que servem de proteção ou suporte delas, fazem parte de um mesmo contínuo topológico. Interessante porque canaliza, orienta, organiza as energias da criança, dando-Ihes forma de atividade ou ocupação. Informativo porque, nesse contexto, ela pode aprender sobre as características dos objetos, os conteúdos

\footnotetext{
${ }^{4}$ De forma literal, ensina a autora que "as atividades lúdicas, juntamente com a boa pretensão dos educadores, são caminhos que contribuem para o bem-estar e entretenimento das crianças, garantindo-lhes uma agradável estadia na creche ou escola" (MALUF, 2008, p.11).

${ }^{5}$ Usaremos aqui a definição de criança e infância confeccionadas por Marcos Cesar de Freitas e Moysés Kuhlmann Jr: "podemos compreender a infância como a concepção ou a representação que os adultos fazem sobre o período inicial da vida, ou como o próprio período vivido pela criança, o sujeito real que vive essa fase da vida" (FREITAS; KUHLMANN, 2002, p. 7), bem como, a definição de criança expressa nas Diretrizes Curriculares Nacionais para a Educação Infantil (BRASIL, 2010, p. 12) que a define como "sujeito histórico e de direitos que, nas interações, relações e práticas cotidianas que vivencia, constrói sua identidade pessoal e coletiva, brinca, imagina, fantasia, deseja, aprende, observa, experimenta, narra, questiona e constrói sentidos sobre a natureza e a sociedade, produzindo cultura".
} 
pensados ou imaginados. O brincar é agradável por si mesmo, aqui e agora.

Portanto, através do jogo, "a criança torna-se capaz de explorar e refletir sobre a realidade em que esta inserida, buscando soluções e hipóteses para os possíveis conflitos" do seu cotidiano, além de estabelecer relações entre as regras e valores, apropriando-se progressivamente "das diversas linguagens corporais" (LOBO, 2013, p.12), favorecendo a autoestima, autoconfiança, autonomia, independência, entre outras habilidades.

Em suma, os jogos e as brincadeiras devem fazer parte do cotidiano escolar das crianças, nas diversas áreas do conhecimento, reconhecendo-os como mecanismos de identificação cultural e formação educativa na vida humana, respeitando as suas capacidades próprias e reconhecendo que cada indivíduo tem seu ritmo (LOPES, 2002).

Contudo, o jogo deve ser visto, como um instrumento de apoio e auxílio na construção da identidade pessoal das crianças, assim como, para a exploração da imaginação, criatividade e construção do pensamento crítico e participativo, auxiliando na formação de cidadãos com condutas sociais aptas para as necessidades de uma sociedade que se encontra em constantes modificações e transformações.

Assim:

Para brincar com uma criança, não precisamos apenas da técnica e da teoria, mas é necessário termos o prazer de brincar, principalmente associado à ingenuidade de um mundo mágico, com encantos, conquistas e descobertas. Quando uma criança nasce, precisa de intimidade e proteção de sua mãe; assim, com o brincar estabelecemos essa intimidade e confiança no vínculo. No brincar, a criança está comprovando a realidade e discriminando as ameaças internas, descarregando suas fantasias e explorando na realidade externa sua capacidade e necessidades, de acordo com o seu desenvolvimento psicossexual (SILVA, 2009, p.38).

Por fim, para respaldar as propostas e objetivos expostos, a presente pesquisa baseia-se em revisão bibliográfica da literatura científica, buscando unir-se às dis- cussões já construídas e ampliar o repertório científico que embasa a temática. Neste sentido, a pesquisa une-se às propostas de Mazi e Lopes (2016); Silva (2009); Kishimoto (2008; 2010); Maluf (2008) e outros pesquisadores que se debruçam a contribuir com o tema.

\section{A IMPORTÂNCIA DO LÚDICO NA EDUCAÇÃO IN- FANTIL PARA O DESENVOLVIMENTO DO ENSINO APRENDIZAGEM}

Atualmente muito se tem discutido e debatidos nas propostas de ensino e currículos escolares a importância de se trabalhar e introduzir atividades lúdicas no ambiente escolar. E esse fator, inicia-se primordialmente na Educação Infantil, onde a criança tem o seu primeiro contato social, fora do seio familiar.

Quando nos referimos as atividades lúdicas devemos ressaltar que esse universo é bastante amplo e requer muito cuidado e planejamento no desenvolvimento de suas atividades, pois este fator pode ser considerado enriquecedor de práticas educativas e ela envolve os jogos, as brincadeiras e os brinquedos (KISHIMOTO, 2008).

Os jogos, brinquedos e as brincadeiras fazem parte da rotina da criança, ou seja, na escola, na rua, no parque, em casa ou em outros ambientes sociais. Portanto, essas atividades são tanto fonte de lazer como facilitadores no seu processo de aprendizagem nas mais diversas áreas do conhecimento (KISHIMOTO, 2010). Ainda segundo Mazi e Lopes (2016, p.57) "o ato de brincar possibilita o processo de aprendizagem da criança, pois facilita a construção da reflexão, autonomia e da criatividade, estabelecendo, desta forma, uma relação estreita entre jogo e aprendizagem".

Contudo, é importante destacar que brincar na escola é diferente de brincar em casa, na rua ou em outros lugares. Podemos dizer que a vida na escola é regida por normas institucionais que orientam e manipulam as ações das pessoas e, naturalmente, essas normas estão presentes, também, na atividade da criança (MIRANDA; SANTOS; RODRIGUES, 2014). Assim, as brincadeiras e os jogos têm uma especificidade quando ocorrem na escola, pois são mediadas pelas normas da instituição e devem ser vistas, com um olhar atento do professor, onde o mesmo observará o desenvolvimento de seus alunos, intervindo sempre que necessário para a construção de sua identidade e autonomia (KISHIMO- 
TO, 2010). Portanto, investir em atividades lúdicas no contexto escolar, torna-se um fator primordial e inerente. Essas operações, quando bem delineadas, estimulam o pensamento, a criatividade, o raciocínio, a capacidade, a sociabilização, a imaginação, a oralidade, a espontaneidade e o respeito mútuo. $\mathrm{O}$ ato de os educadores fornecerem os jogos e as brincadeiras nas atividades escolares são pré-requisitos, tanto para o desenvolvimento da criança, quanto para a construção do conhecimento, processos esses intimamente interligados a um único intuito, - o tão almejado ensino e aprendizagem (KISHIMOTO, 2008).

Para tanto, é indispensável à conscientização de que utilizar-se de ferramentas lúdicas como o jogo em espaços físicos fará com que as crianças reinventem situações, amadureçam sua capacidade de socializar e respeitar regras presentes nos jogos (MAZI; LOPES, 2016). Ora, é brincando que elas constroem suas identidades e seus conhecimentos, é brincando que conquistam sua autonomia, é brincando que desenvolvem sua linguagem, é brincando que melhoram sua concentração e atenção, que aprendem a enfrentar e a lidar com seus medos e aflições, que expressam seus sentimentos e opiniões, que aprendem a entender e agir no mundo o qual as cerca, que descobrem as suas limitações, enfim, é brincando que elas aprimoram as suas habilidades e melhoram o seu convívio com os demais ao seu redor (BRASIL, 1998).

Nesta conjuntura, o Referencial Curricular Nacional para a Educação Infantil (RCNEI) prescreve que:

As crianças constroem o conhecimento a partir das interações que estabelecem com as outras pessoas e com o meio em que vivem. O conhecimento não se constitui em cópia da realidade, mas sim, fruto de um intenso trabaIho de criação, significação e ressignificação (BRASIL, 1998, p. 21).

O lúdico é essencial na vida da criança, e as instituições de ensinos devem oferecer para as mesmas, essa ferramenta tão importante para a construção de sua identidade (FRIEDMANN, 2012), conforme apontam as Diretrizes Curriculares Nacionais para a Educação Infantil ao mencionar que "as práticas pedagógicas que compõem a proposta curricular da Educação Infantil devem ter como eixos norteadores as interações e a brincadeira" (BRASIL, 2010, p.25). Neste contexto, as atividades lúdicas são atividades essenciais no dia a dia ${ }^{6}$ principalmente quando estão relacionadas ao desenvolvimento da educação infantil. São instrumentos importantes porque dá o poder à criança para tomar decisões, expressar sentimentos e valores, conhecer a si mesmo, os outros e o mundo, repetir ações prazerosas, partilhar brincadeiras com o outro, expressar sua cultura para compreeendê-lo, usar o corpo, os sentidos, os movimentos, as várias linguagens, para experimentar situações que lhe chamam a atenção, solucionar problemas e criar (BOTELLE, 2016). Portanto, é no plano da imaginação que os jogos e as brincadeiras se destacam pela mobilização dos significados. Enfim, sua importância se relaciona com a cultura da infância que coloca o lúdico como uma ferramenta para a criança se expressar, aprender e se desenvolver como um sujeito em constante formação para o pleno domínio da cidadania (KISHIMOTO, 2010). Neste cenário:

Embora com diferentes ênfases, todas as teorias do jogo e da brincadeira, desde as clássicas até as mais recentes, apontam para a importância do túdico como meio privilegiado de expressão e de aprendizagem infantil, reconhecendo não haver nada significativo na estruturação e no desenvolvimento de uma criança que não passe pelo brincar (RODULFO, 1990 apud SCHWARTZ, 2004, p. 04).

\subsection{A importância dos jogos na aprendizagem das crianças.}

Como já foi dito anteriormente, a aprendizagem com jogos lúdicos tornou o ensino mais prazeroso e significativo. Porém, esse conceito nem sempre foi tão am-

\footnotetext{
${ }^{6}$ Marília Scorzoni e Elaine Mota complementam "a abordagem lúdica apresenta-se, assim, como ferramenta que viabiliza uma nova configuração de ensino que articula as diferentes linguagens, os diferentes gêneros, os diferentes sujeitos e as diferentes possibilidades de produzir sentido pela linguagem (SCORZONI; MOTA, 2020, p.55).
} 
plo. O trabalho com jogos aplicados na educação básica desenvolveu-se vagarosamente e penetrou tardiamente no âmbito escolar, mas trouxe transformações relevantes fazendo com que o estudo tornasse divertido, eficaz e eficiente (MARTINS, 2012).

Desde o nascimento, a criança está inserida em um ambiente no qual os amplos conhecimentos matemáticos são parte integrante de sua vida diária. Envolvidas em situações como os números, relações entre quantidades, noções sobre/espaço, elas começam a fazer uso de recursos próprios e pouco convencionais, recorrendo às operações para a resolução de problemas cotidianos (PIAGET, 1976).

Contudo, a criança constrói seus conhecimentos matemáticos por meio de sucessivas reorganizações ao longo de sua vida, elaborando uma serie de idéias e hipóteses provisórias antes de compreender um objeto em toda a sua complexidade (PIAGET, 1976).

Para Piaget (1976, p. 21):

O jogo é, portanto, sob as suas formas essenciais de exercício sensório-motor e de simbolismo, uma assimilação do real à atividade própria, fornecendo a esta seu alimento necessário e transformando o real em função das necessidades múltiplas do eu. Por isso, os métodos ativos de educação das crianças exigem que se forneça às crianças um material conveniente, a fim de que, jogando elas cheguem a assimilar as realidades intelectuais que, sem isso, permanecem exteriores à inteligência infantil.

Para tanto, os pais e educadores devem estar atentos para as atitudes da criança durante as brincadeiras e jogos, pois ela expressa a sua realidade, manifesta vontades e desejos, além de estabelecer relações cognitivas com as suas experiências de vida (FRIEDMANN, 2012).

Contudo, os jogos lúdicos não devem ser vistos como um passatempo em sala de aula, mas sim, como ferramentas de suporte ao professor. E quando utilizadas de forma adequada, tornam o processo de ensino e aprendizagem mais significativo, prazeroso, harmonioso e eficiente. Neste sentido, Friedmann (2012, p.18) preleciona:

\begin{abstract}
Os jogos e brincadeiras potencializam o aprendizado das crianças, isso faz com que elas se aventurem, entrando no mundo de suas fantasias. As crianças quando chegam à escola, estão abertas ao aprendizado, e é nesse momento que elas desenvolvem suas potencialidades que vão carregar consigo durante toda a vida.
\end{abstract}

É fundamental a importância de se trabalhar os jogos no processo pedagógico. E é neste sentido que os jogos lúdicos ganham espaço primordial em sala, pois proporcionam às crianças que elas aprendam de forma saudável e divertida, e não apenas com fatigantes métodos tradicionais de exercícios, - extensos e repetitivos (BRASIL, 1998).

O professor, ao planejar suas ações, deve pensar no que pretende alcançar, para qual criança está ensinando, se os conteúdos abordados atingiram os objetivos de sua turma e qual a importância de se escorar sobre novas ferramentas em classe, e assim oferecer às crianças novos recursos pedagógicos em sala. Como dito, o lúdico e os jogos pedagógicos são ingredientes importantíssimos que devem estar inseridos nas rotinas das crianças na escola, pois os mesmos cumprem papel fundamental em suas vidas, além de ser um processo integrador e facilitador das novas aprendizagens, alcançando assim bons resultados no ambiente escolar (FUSSARI, 1988).

\subsection{O Lúdico, a Brincadeira e o Jogo}

As palavras marcam nossas relações interpessoais, assim como o brincar (que vem do latim vinculum, que significa vínculo, união). Então, o brincar é uma forma de linguagem pela qual a criança se dirige aos outros (SCHWARTZ, 2004, p. 10)

O ser humano é um "autor" dotado de vontades, tristezas, alegrias, angústias, sonhos, fantasias, medos, etc. Neste seguimento, cabe ressaltar que a necessidade de brincar é fator relevante na construção de sua vida, - principalmente na fase infantil -, onde ela estabelece seus primeiros contatos de amizade, manifesta suas vivências, suas opiniões, sua cultura, dentre outras. Por isso, o ato de brincar se torna indispensável 
para a formação de sua identidade, autonomia, equilíbrio, pensamento, construção pessoal e interpessoal e contribui para a uma vida saudável, física e mental (CHATEAU, 1987).

Para Chateau (1987, p.14), "uma criança que não sabe brincar, uma miniatura de velho, será um adulto que não saberá pensar".

É importante propalar que o brincar deve ser sempre estruturado de forma significativa e que quando aliado ao processo de aprender, transforma-se em ferramenta e alternativas importantíssimas para lidar com o fracasso escolar. E estes recursos pedagógicos, como bem preconiza Fussari (1988) quando bem planejados pelo professor, acabam por possibilitar melhorias na qualidade de ensino de forma saudável, harmoniosa e prazerosa.

Neste seguimento de raciocínio, ouçamos Vygotsky (1989, p.37):

O lúdico só pode ser considerado educativo quando desperta o interesse do aluno pela disciplina, portanto os professores precisam aproveitar o mesmo como facilitador da aprendizagem. Os jogos e brincadeiras despertam nas crianças o gosto pela vida.

É necessário ressaltar que o educador deverá ter um olhar atento quanto à utilização e desenvolvimento desses métodos, pois os mesmos deverão ser aplicados de forma que atinjam o desenvolvimento de saberes, de habilidades, de hábitos, de atitudes e de pensamentos ${ }^{7}$. Consequentemente, valorizar o histórico de experiências e de aprendizagens e a bagagem de vida que o aluno traz para o interior da escola, acaba por favorecer o enriquecimento dos conteúdos e dos componentes curriculares escolares (BRASIL, 1998).

Segundo ensina Luckesi (1986) os métodos e os recursos lúdicos de ensino e aprendizagem organizados pelos docentes por meio de etapas sequenciadas e registros pedagógicos, facilitam a organização e o aperfeiçoamento de sua avaliação, podendo ser um diagnóstico que sinaliza os resultados obtidos pelo mesmo como satisfatórios ou insatisfatórios. Essas ações poderão ser discutidas, replanejadas, compartilhadas entre os colegas de profissão e equipe gestora, buscando soluções que visam o sucesso escolar.

E Luckesi (1986, p. 70) complementa:

\begin{abstract}
A avaliação deve ser sempre vista como um meio e não como um fim em si mesmo. Considerando o aluno como um ser ativo na construção do próprio conhecimento, seu potencial e ritmo de aprendizagem devem ser respeitados. Um mesmo conteúdo pode ser apreendido de formas diferentes, dependendo das condições e da capacidade de percepção e de raciocínio de cada aluno. Além disso, cada conteúdo deve ser trabalhado de acordo com os objetos que o professor deseja alcança e através de diferentes metodologias.
\end{abstract}

Contudo, a avaliação reflete as concepções de educação dos professores e não deve ser classificatória, punitiva, autoritária ou controladora e, sim, um indicador de mudanças necessário para que o próprio professor analise a eficácia dos seus métodos de ensino. $E$ ela não deve ser considerada como uma etapa final, mas como um elo entre a aprendizagem e os objetivos a serem alcançados. É importante pensarmos que o desenvolvimento e aprendizagem não terminam com o final de cada ano ou ciclo, mas que irá prosseguir durante a educação escolar e também no meio social em que cada indivíduo está inserido (LUCKESI, 1986).

A brincadeira lúdica como disserta Piaget (1976), auxiliam as crianças no processo de aprendizagem e contribuem para a sua formação e desenvolvimento global, promovendo subsídios eficazes e significativos em sala de aula, além de ser um processo integrador entre os aspectos motores, cognitivos, afetivos e sociais. Portanto, uma boa opção de se trabalhar de maneira lúdica em sala de aula é se amparar nos jogos como recursos didáticos pedagógicos, para aquisição do conhecimento lógico-abstrato na Matemática e na Língua Portuguesa. Dessa forma, quando se opta por inserir o

\footnotetext{
${ }^{7}$ Schwartz (2004, p. 10-11) ensina que "para brincar com o processo de alfabetização, a professora poderia usar menos ditados e cópias e propor atividades que levassem a criança a: * jogar com índices (por exemplo, procurar um animal imaginário, como o coelho da Páscoa, a partir de suas pegadas no chão); * brincar com os sinais (o sinal da escola, o sinal para começar um jogo); ${ }^{*}$ inventar símbolos (desenhos que simbolizem a criança, álbum de fotos); * jogar com signos (criar palavras, nomes, apelidos, marcas, rótulos)
} 
ensino de matemática e de alfabetização por meio dos jogos, deve-se levar em conta a importância e a definição dos conteúdos e dos conceitos a serem tratados, sem o abandono das habilidades presentes nas brincadeiras e do planejamento da ação, como o objetivo de o jogo não se tornar mero lazer, um momento de distração ou falta de compromisso, mas sim, de potencializar capacidades, ampliar as possibilidades dos alunos de pensarem, agirem, compreenderem e transformarem a realidade (CHATEAU, 1987).

Ao se elencar os diversos objetivos que o ensino de matemática propõe, destaca-se o fato de que ensinar a resolver problemas com a utilização de recursos como o jogo em sala contribuirá na compreensão do mundo, na tomada de decisões com independência, agindo como produtores de conhecimento e não meros executores de instruções. O lúdico como método pedagógico prioriza a liberdade de expressão e criação, favorecendo nos discentes a espontaneidade e auxiliando na concentração, memória, imitação e imaginação e no seu processo de construção global ao qual a cerca (FRIEDMANN, 2012).

\section{EDUCADORES: FORMAÇÃO E ATUAÇÃO NA UTI- LIZAÇÃO DOS JOGOS COMO RECURSO DIDÁTICO PEDAGÓGICO}

$\mathrm{Na}$ atualidade existe uma grande preocupação em oferecer, nas instituições escolares, um ensino versátil, que valorize as experiências e os conhecimentos prévios das crianças, ou seja, um ensino divorciado de conhecimentos prontos, tradicionais, enfatizados ou mecânicos. Sem fartas normas, nem regras profusas, apenas uma aprendizagem que proporcione no aluno a construção do seu próprio conhecimento, um ensino onde o educador deverá ser, ao mesmo tempo, mediador e orientador das atividades desenvolvidas (BRASIL, 1999).

Como salienta Fussari (1998), vale ressaltar que, para que uma aprendizagem ocorra com sucesso, de forma lúdica e prazerosa, é necessário que o professor tenha preparo e uma boa formação, planejamento suas ações e as metodologias utilizadas, que aja com criatividade e saiba compreender o alunado. $\mathrm{O}$ educador necessita de habilidade em trabalhar com o raciocínio lógico da criança, fazendo-a estabelecer relações entre o concreto e o simbólico. É papel fundamental do professor, analisar criticamente e definir a proposta curricular, preparar os alunos para uma participação ativa dentro da sociedade em que está inserido, verificar a metodologia adequada para a aplicabilidade dos conceitos que serão desenvolvidos, adequando-os à sua clientela, a fim de que a aprendizagem atinja o objetivo almejado. Caberá ao docente uma atitude de permanente interrogação, reflexão e investigação, proporcionando um ambiente motivador para que ocorra a aprendizagem em um contexto contagiante e emocionante (DALLABONA; MENDES, 2004; MAZI; LOPES, 2016).

Assim:

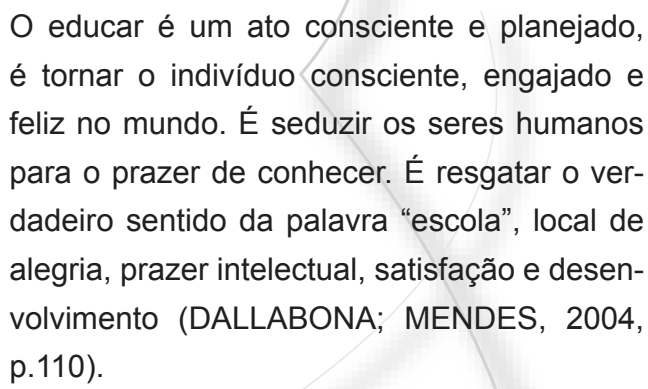

Diante disso, é necessário que professor esteja em constante estudo e pesquisa enriquecendo sua formação. É fundamental que o mesmo, ao planejar suas ações didáticas, reflita primeiramente sobre o - "para que ensinar"-, ou seja, quais os objetivos que envolvem o seu fazer docente, planejando de forma consciente e coerente os conteúdos, a metodologia, recurso mais ajustado para ser utilizado, o que espera que o aluno alcance, a sua prática docente e a avaliação a ser diagnosticada. Nesta chave de análise, pode-se inferir que o ato de planejar é de extrema relevância para uma correta proposta pedagógica. Este é um processo que envolve a atuação concreta dos educandos no cotidiano do seu trabalho pedagógico, permitindo a todos uma melhor interação e aproximação entre o conteúdo a ser estudado e o que se pretendo que o aluno alcance (FUSSARI, 1998).

Nesse sentido, ainda segundo Fussari, (1988), o planejamento envolve a fase anterior ao início das aulas, o durante e o depois, significando o exercício contínuo de ação-reflexão-ação, ao longo de todo o ano e não num período preestabelecido e restrito, podendo sofrer alterações sempre que necessário, adequando-se às situações que surgem no decorrer do processo.

Desta feita, o professor deve entender que "a criança é um ser pleno de potencialidades", e que uma boa proposta pedagógica pode estimular suas capacidades 
e proporcionar a ela oportunidades de conhecimento e desenvolvimento, ampliando as possibilidades de compreensão do mundo as que cercam (BROGE, 2017; DALLABONA; MENDES, 2014) ${ }^{8}$.

É nessa perspectiva, que as atividades lúdicas e os jogos ganham principal enfoque, pois além de serem instrumentos facilitadores de uma educação de qualidade, permitem que as crianças desenvolvam sua autoestima, interação, respeito ás regras, individualidades, pensamento, raciocínio lógico, oralidade, etc (KISHIMOTHO, 2010).

A criança quando brinca aprende e essa aprendizagem ocorre de um jeito mais harmônico pois ela passa a aprender brincando. As atividades quando são propostas com um quê de lúdico dão mais prazer as pessoas envolvidas, pois a criança consegue aprender o que o professor pretende através de uma brincadeira. Por conta da minha experiência pude perceber que as crianças se "entregam" muito mais nas atividades que se têm brincadeiras do que em atividades mais mecânicas (BROGE, 2017, p.10).

Para isso, o professor deve conhecer e considerar as singularidades das crianças de diferentes idades, assim como a diversidade de hábitos, costumes, valores, crenças, etnias das crianças com as quais trabalham, respeitando suas diferenças e ampliando suas pautas de socialização (KISHIMOTHO, 2010).

Contudo, o educador deve ser constantemente o mediador entre as crianças e os objetos de conhecimento, organizando e propiciando espaços e situações de aprendizagens que articulem os recursos e capacidades afetivas, emocionais, sociais e cognitivas de cada criança aos seus conhecimentos prévios e aos conteúdos referentes aos diferentes campos de conhecimento humano $^{9}$ (BROGE, 2017). No ambiente, o professor cons- titui-se, portanto, como parceiro mais experiente, onde uma boa formação individual contribui de forma significativa as metodologias a serem direcionadas a cada grupo em sala de aula, garantindo-lhes aos alunos um ambiente rico, prazeroso, saudável e eficaz. (BRASIL, 1999).

De acordo com o Referencial Curricular Nacional (BRASIL, 1999), o profissional da educação deve ser polivalente. Ou seja, possuir de uma formação ampla, reflexiva, dialógica, crítica e articulada aos conceitos educacionais, sociais, políticos, históricos, que permitem um perfil docente voltado para uma prática de observação, registro, planejamento e avaliação coerentes. Assim, a figura do professor em sala de aula é de extrema relevância, pois o mesmo tem um papel fundamental no domínio dos conteúdos e conhecimentos transmitidos, além de interagir e incentivar o intercâmbio de troca de experiências no ambiente escolar (BRASIL, 1999).

Desse modo, considera-se que o domínio do planejamento, metodologia e articulação dos componentes curriculares por meio da utilização de jogos lúdicos pedagógicos depende também de muitos fatores, como a formação inicial e continuada dos profissionais da educação, tanto do nível prático como teórico. A meta sempre deve ser levar os alunos ao contato direto da aprendizagem de uma forma harmoniosa, saudável e divertida, onde o aprender de maneira lúdica desperte as habilidades e interação de novos conhecimentos. $O$ Professor da Educação Básica dos diversos níveis de ensino, e especificamente da Educação Infantil e Ensino Fundamental Anos Iniciais, deverá repensar seu trabaIho, pesquisar, discutir com outros docentes e aperfeiçoar-se constantemente. O mesmo terá que saber unir as problemáticas das práticas escolares as suas reflexões e teorias com as dos demais profissionais, de um modo transformador, criativo e compromissado, alcançando dessa forma bons resultados no ensino e aprendizagem escolar (BRASIL, 1999; BROGES, 2017).

Para tanto, vale ressaltar, que o professor neces-

\footnotetext{
${ }^{8}$ Diz Anna Broge "Entender que a criança é um ser pleno de potencialidades é essencial para o educador, pois assim ele saberá, perceberá onde poderá estimular seus alunos para que esse potencial se aprimore. É necessário que o educador tenha sempre em mente que cada criança é única e com isso a maneira de se estimular este potencial também será única. Acredito que esse estímulo do potencial da criança seja mais bem aproveitado nas experiências com intuitos lúdicos, pois quando brincamos, aprendemos com prazer e se aprendemos com prazer conseguimos nos entregar plenamente" (BROGE, 2017, p.18)

9 "Nas brincadeiras dirigidas a criança tem uma meta a alcançar, na qual muitas vezes é estabelecida pelo professor, o educador nesse processo apresenta se como um mediador e parceiro para esse método" (BROGE, 2017, p.33).
} 
sita atualizar-se em relações ao modo de aprender nas novas gerações, o qual envolve o uso de jogos eletrônicos, computadores, internet e aparelhos eletrônicos. Portanto, é necessário que o educador esteja preparado e envolvido com esses novos recursos, aproximando os conteúdos a serem trabalhados com a realidade dos educandos. O educador deve desenvolver, ainda, a capacidade de apreciação e avaliação crítica das diversas formas de produções comunicativas, desempenhando em sala um papel motivador de novos conhecimentos e recursos pedagógicos (LUCKESI, 1986).

Por fim, podemos apontar que atividades lúdicas e os jogos pedagógicos, são importantes para a melhoria da educação em sala de aula, pois os mesmos provocam uma aprendizagem significativa que ocorre gradativamente e de forma natural, e que o professor deve fomentar esses recursos em classe, de maneira planejada e organizada, valorizando as experiências de cada indivíduo, ampliando a sua capacidade de pensar, raciocinar, criar, inventar, sociabilizar, interagir e dialogar, alcançando assim resultados significativos no ambiente escolar (CHATEAU, 1987).

\section{CONSIDERAÇÕES FINAIS}

O ser humano nasceu para aprender, descobrir, inventar, reinventar diversos conhecimentos passando entre os mais simples até os mais complexos (DEWEY, 1967 apud BARBOSA; FREITAS, 2006). A sociedade atual vive em constante mudança. As crianças e jovens, demonstrando insatisfação no ambiente escolar, onde muitas vezes os conhecimentos transmitidos em sala de aula se tornam maçantes, extensos e desinteressantes, buscam cada vez mais por um ensino motivador e prazeroso,

A educação atualmente está em constantes transformações. Muito se tem discutido sobre a escola que queremos para o futuro. Dessa forma, muito se tem pesquisado e debatido sobre a importância do trabaIho lúdico no contexto escolar, onde este deve ser um mecanismo facilitador de novos conceitos de aprendizagens como: habilidades, pensamentos, criatividades, atitudes, valores, conhecimentos, práticas pedagógicas, planejamentos escolares, sondagens, observações, avaliações, etc.

Portanto, o brincar é uma ferramenta basilar de comunicação e interação, pois, por meio dela que a crian- ça reproduz o seu cotidiano, podendo expressar seus desejos, vontades, pensamentos, autonomia, auxiliando na construção do desenvolvimento das suas relações sociais e interpessoais. Para tanto, o brincar faz parte do processo de aprendizagem de todo o ser humano, começando pela infância onde as crianças poderão desenvolver suas habilidades físicas, motoras e cognitivas. Como vimos, é neste sentido que o professor deve proporcionar atividades lúdicas, como as brincadeiras e jogos onde possam estimular em seus alunos de forma prazerosa e saudável. É brincando que a criança reinventa o seu mundo imaginário, imitam os adultos e construindo sua autonomia, independência e pensamento.

Para Vygotsky (1984 apud SILVA; SANTOS, 2009, p.7):

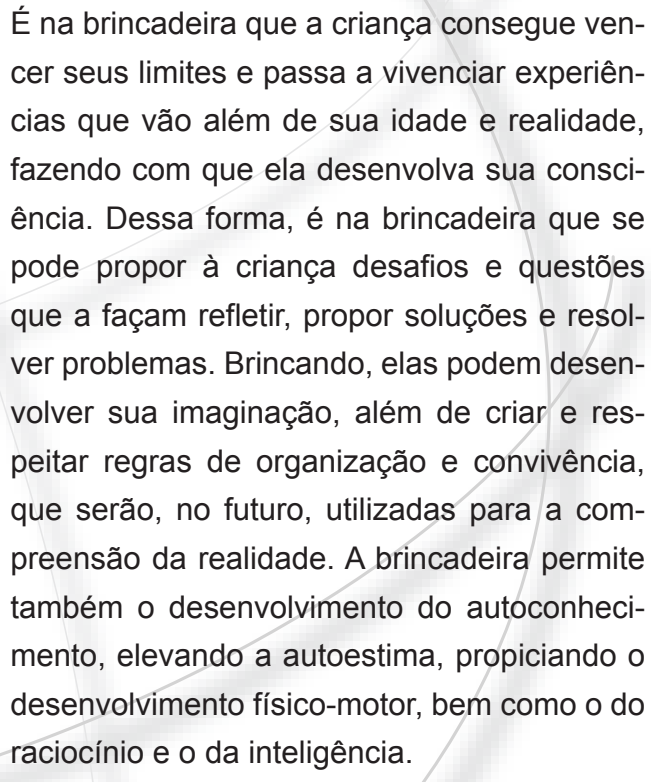

Dessa forma, a melhoria e o sucesso da Educação Infantil são de responsabilidades de todos os agentes sociais. São ações conjuntas e bem planejadas que podem resultar em índices melhores ao final ciclo do ensino médio, estendendo-se na fase adulta e ao mundo acadêmico e do trabalho.

Por fim, como enfatiza Lopes (2002) o universo lúdico, quando explorado de forma enriquecedora, auxilia na construção e formação de cidadãos mais críticos, conscientes, participativos, independentes e autônomos, sabendo agir de maneira ativa, diante dos vagaIhões da vida. 


\section{REFERÊNCIAS}

BARBOSA, Alessandra Alves; FREITAS, Maria Auxiliadora Aguiar de. $O$ Lúdico no processo de aprendizagem e de desenvolvimento da criança. 2006. 38 f. Trabalho de Conclusão de Curso (Pedagogia). UniCEUB, Brasília, 2006.

BOTELLE, Andréa. Psicomotricidade: a importância do lúdico na infância. Rio de Janeiro: Autografia, 2016.

BRASIL. Ministério da Educação. Secretaria de Educação. Referencial Curricular Nacional para a Educação Infantil. Brasília: MEC/SEF, 1998.

BRASIL. Ministério da Educação. Secretaria de Educação Fundamental. Referencial Curricular Nacional para o Ensino Fundamental. Brasília: MEC/SEE, 1999.

BRASIL. Ministério da Educação. Secretaria de Educação Básica. Diretrizes curriculares nacionais para a educação infantil. Brasília: MEC/SEB, 2010.

BROGE, Anna Adélia Abreu. Aprendizagem através do Lúdico na Educação Infantil: o mundo da criança é o universo. 2017. $40 \mathrm{f}$. Trabalho de Conclusão de Curso (Licenciatura em Pedagogia). Universidade Federal do Rio de Janeiro - UFRJ, Rio de Janeiro, 2017.

CHATEAU, Jean. O Jogo e a Criança. São Paulo: Summus, 1987.

DALLABONA, Sandra Regina; MENDES, Sueli Maria Schmitt. O lúdico na Educação Infantil: jogar, brincar, uma forma de educar. Vozes, 2004.

FREITAS, Marcos Cezar de.; KUHLMANN JR, Moysés. (Orgs.). Os intelectuais na história da infância. São Paulo: Cortez, 2002.

FRIEDMANN, Adriana. $\mathbf{O}$ direito de brincar: a brinquedoteca. São Paulo: ABRINQ, 2012.

FUSSARI, José Cerchi. O Papel do planejamento na formação do educador. São Paulo: SE/CENP, 1988.

KISHIMOTO, Tizuki Morchida. Jogo, brinquedo, brin- cadeira e a educação. São Paulo: Cortez, 2008.

Brinquedos e brincadeiras na Educação Infantil. Petrópolis, Vozes, 2010.

LOBO, Jadiane Cristina. A importância do brincar na Educação Infantil para crianças de $\mathbf{3}$ a $\mathbf{4}$ anos. 2013. 76 f. Trabalho de Conclusão de Curso (Pedagogia) Centro Universitário Católico Salesiano, Lins, 2013.

LOPES, Vanessa Gomes. Linguagem do corpo e movimento. Curitiba: FAEL, 2002.

LUCKESI, Carlos Cipriano. Avaliação Educacional. Revista Ande. São Paulo: Cortez, 1986.

MACEDO, Lino de. Os jogos e o lúdico na aprendizagem escolar. Porto Alegre: Artmed, 2007.

MALUF, Angela Cristina Munhoz. Atividades lúdicas para a educação infantil. Conceitos, orientações e práticas. Petrópolis: Vozes, 2008.

MARTINS, Emerson de França. A importância dos jogos na educação fundamental de $6^{\circ}$ ao $9^{\circ}$ ano na Escola Estadual de Cabeceiras - GO. Monografia (Licenciatura em Educação Física) - Universidade de Brasília, Unb, Planaltina, 2012.

MAZI, Izabela Maria; LOPES, Mario Marcos. Perspectivas do brincar na educação infantil: aspectos teóricos e a prática docente. In: FERREIRA, Emerson Benedito; LOPES, Mario Marcos (Org.). Pesquisas em educação: escola, infância e sexualidade. 1.ed. São Carlos: Pedro \& João Editores, 2016, p. 57-97.

MIRANDA, Daiana Barth; SANTOS, Patrícia Gonçalves dos; RODRIGUES, Samira de Souza. A importância dos jogos e brincadeiras para a Educação Infantil. 2014. 45 f. Trabalho de Conclusão de Curso (Pedagogia). Faculdade Multivix-Serra, Serra, 2014.

PIAGET, Jean. Psicologia e Pedagogia. Tradução de Dirceu Accioly Lindoso e Rosa Maria Ribeiro da Silva. Rio de Janeiro: Forense Universitária, 1976. 


\section{rejvista educação}

espaço escolar como criança e crescimento. São Paulo: Arte \& Ciência, 2003.

SCHWARTZ, Gisele Maria (org.). Dinâmica Lúdica: novos olhares. Barueri: Manole, 2004.

SCORZONI, Marília Ferranti Marques; MOTA, Elaine Christina. Base Nacional Comum Curricular e Ludicidade: uma experiência no processo de formação do docente de língua portuguesa. In: FERREIRA, Emerson Benedito; LOPES, Mário Marcos. Pesquisas em educação: cidadania, ensino e sociedade. São Carlos: Pedro \& João Editores, 2020.

SILVA, Aline Fernandes Felix da; SANTOS, Ellen Costa Machado dos. A importância do brincar na Educação Infantil. 2009. 36 f. Trabalho de Conclusão de Curso (Especialização). Universidade Federal Rural do Rio de Janeiro - UFRRJ, Rio de Janeiro, 2009.

VYGOTSKY, Lev Semenovitch. A Formação Social da Mente. São Paulo: Martins Fontes, 1989. 